\title{
A-Melanocyte-Stimulating Hormone Protects Early Diabetic Retina from Blood- Retinal Barrier Breakdown and Vascular Leakage via MC4R
}

\author{
Siwei Caia Qianhui Yanga Mengzhu Hou ${ }^{\mathrm{b}}$ Qian Han ${ }^{\mathrm{a}}$ Hanyu Zhang ${ }^{\mathrm{a}}$ \\ Jiantao Wang ${ }^{c}$ Chen $\mathrm{Q}^{\mathrm{a}}$ Qiyu Bo ${ }^{\mathrm{a}}$ Yusha Ru Wei Yang $^{\mathrm{a}}$ Zhongxiu Gu ${ }^{\mathrm{a}}$ \\ Ruihua Weia Yunshan Cao ${ }^{\text {d, e }}$ Xiaorong Lia Yan Zhanga \\ aTianjin Medical University Eye Hospital, Tianjin Medical University Eye Institute, College of Optometry \\ and Ophthalmology, Tianjin Medical University, Tianjin, ${ }^{\mathrm{b} T i a n j i n ~ M e d i c a l ~ U n i v e r s i t y, ~ C o l l e g e ~ o f ~}$ \\ Biomedical Engineering and Technology, Tianjin, cShenzhen Eye Hospital, Shenzhen, Guangdong \\ Province, ${ }^{\mathrm{d} D e p a r t m e n t}$ of Cardiology, Gansu Provincial Hospital, Lanzhou, Gansu Province, eDepartment \\ of Heart Failure, Shanghai East Hospital, Tongji University School of Medicine, Research Center for \\ Translational Medicine, Shanghai East Hospital, Tongji University School of Medicine, Shanghai, China
}

\section{Key Words}

Diabetic retinopathy $\cdot \alpha$-MSH - Blood-retinal barrier breakdown - Vascular leakage Proinflammatory factor $\cdot$ Tight junction

\begin{abstract}
Background/Aims: Blood-retinal barrier (BRB) breakdown and vascular leakage is the leading cause of blindness of diabetic retinopathy (DR). Hyperglycemia-induced oxidative stress and inflammation are primary pathogenic factors of this severe DR complication. An effective interventional modality against the pathogenic factors during early DR is needed to curb BRB breakdown and vascular leakage. This study sought to examine the protective effects of $\alpha$-Melanocyte-stimulating hormone $(\alpha-\mathrm{MSH})$ on early diabetic retina against vascular hyperpermeability, electrophysiological dysfunction, and morphological deterioration in a rat model of diabetes and probe the mechanisms underlying the $\alpha-\mathrm{MSH}^{\prime} \mathrm{s}$ anti-hyperpermeability in both rodent retinas and simian retinal vascular endothelial cells (RF6A). Methods: Sprague Dawley rats were injected through tail vein with streptozotocin to induce diabetes. The rats were intravitreally injected with $\alpha-\mathrm{MSH}$ or saline at Week 1 and 3 after hyperglycemia. In another 2 weeks, Evans blue assay, transmission electron microscopy, electroretinogram (ERG), and hematoxylin and eosin (H\&E) staining were performed to examine the protective effects of $\alpha-\mathrm{MSH}$ in diabetic retinas. The expression of pro-inflammatory factors and tight junction at mRNA and protein levels in retinas was analyzed. Finally, the $\alpha$-MSH's anti-hyperpermeability

S. Cai, Q. Yang and M. Hou contributed equally to this work.

Yunshan Cao,

Xiaorong Li and Yan Zhang

Department of Cardiology، Gansu Provincial Hospital, Lanzhou, Gansu Province,

Tianjin Medical University Eye Hospital, Tianjin Medical University Eye Institute, Tianjin

(China);E-Mail yunshancao@126.com,xli@tmu.edu.cn, yanzhang04@tmu.edu.cn
\end{abstract}

\section{KARGER}


was confirmed in a high glucose (HG)-treated RF6A cell monolayer transwell culture by transendothelial electrical resistance (TEER) measurement and a fluorescein isothiocyanateDextran assay. Universal or specific melanocortin receptor (MCR) blockers were also employed to elucidate the MCR subtype mediating $\alpha$-MSH's protection. Results: Evans blue assay showed that BRB breakdown and vascular leakage was detected, and rescued by $\alpha-M S H$ both qualitatively and quantitatively in early diabetic retinas; electron microscopy revealed substantially improved retinal and choroidal vessel ultrastructures in $\alpha-\mathrm{MSH}$-treated diabetic retinas; scotopic ERG suggested partial rescue of functional defects by $\alpha-\mathrm{MSH}$ in diabetic retinas; and $H \& E$ staining revealed significantly increased thickness of all layers in $\alpha-M S H$-treated diabetic retinas. Mechanistically, $\alpha-\mathrm{MSH}$ corrected aberrant transcript and protein expression of pro-inflammatory factor and tight junction genes in the diseased retinas; moreover, it prevented abnormal changes in TEER and permeability in HG-stimulated RF6A cells, and this anti-hyperpermeability was abolished by a universal MCR blocker or an antagonist specific to MC4R. Conclusions: This study showed previously undescribed protective effects of $\alpha-M S H$ on inhibiting BRB breakdown and vascular leakage, improving electrophysiological functions and morphology in early diabetic retinas, which may be due to its down-regulating proinflammatory factors and augmenting tight junctions. $\alpha-\mathrm{MSH}$ acts predominantly on MC4R to antagonize hyperpermeability in retinal microvessel endothelial cells.

(C) 2018 The Author(s)

Published by S. Karger AG, Basel

\section{Introduction}

Diabetic macular edema (DME) is one of the severe complications of diabetic retinopathy (DR), and is becoming the leading cause of vision loss in DR [1]. The DME is mainly caused by breakdown of blood-retinal barrier (BRB) and retinal vascular leakage [2]. Research has shown that the pathogenic factors, including hyperglycemia, oxidative stress, and proinflammatory microenvironment, during early stage of DR cause diffusive BRB breakdown and vascular leakage [3]. If these were not properly treated in early DR, the elevated levels of vascular endothelial growth factor (VEGF) induced by hypoxia and ischemia [4], together with the pathologies in retinal vasculature at the late stage of DR, such as acellular capillaries, microaneurysms, and microvessel lumen stenosis [5], would result in an elevated hydrostatic pressure in capillary lumens and leakage of macromolecules, proteins and electrolytes into tissue space with sera, thereby increasing interstitial osmolarity and exacerbating vascular leakage [3]. The exacerbated vascular leakage causes macular edema in the late DR, which entails more difficult, yet often less satisfactory therapeutic managements [6]. The currently available therapeutic modalities to DME include laser photocoagulation, intravitreal injections of glucocorticoid hormone or anti-VEGF drugs [7]. These modalities demonstrate certain efficacies, however, the potential side effects such as retinal damage and elevated intraocular pressure, and the considerable portion of unresponsiveness in patients as well as the prohibitive cost are of major concerns [8]. Therefore, the search for a novel and effective interventional modality to the BRB breakdown and vascular leakage during early DR is of primary clinical importance.

$\alpha$-Melanocyte-stimulating hormone $(\alpha-\mathrm{MSH})$ is a widely-distributed 13 -amino acid peptide derived from proopiomelanocortin [9]. After posttranslational modifications at both termini, $\alpha$-MSH becomes biologically active and binds to its cognate receptors, melanocortin receptors (MCR) $[10,11]$, to regulate physiological functions, including body temperature [12] and metabolism [13]. In the eye, the functions of $\alpha$-MSH include modulating immune responses [14], maintaining immune privileges [15], and inhibiting inflammation [16]. We have shown, in a series of studies that intravitreal injections of $\alpha$-MSH exert anti-oxidative and anti-apoptotic effects in retinal vessels and neuroretina of streptozotocin (STZ)-induced diabetic rats [17]. In addition, $\alpha$-MSH reduces pro-inflammatory microenvironment in diabetic retinas [17]. Whereas oxidative stress and inflammatory mediators are the major pathogenic factors causing BRB breakdown and vascular leakage in early diabetic retina [3]. Therefore, we hypothesize that intravitreal administration of $\alpha$-MSH may protect early 
Cai et al.: A-MSH Protects Early Diabetic Retina from Vascular Leakage

diabetic retina from BRB breakdown and vascular leakage. To test this hypothesis, we continued using the STZ-induced diabetic rats to examine the effects of intravitreal injections of $\alpha$-MSH on BRB function and ultrastructure, as well as on retinal electrophysiological function and general morphology; the molecular mechanisms underlying such effects were investigated; furthermore, we established an in vitro inner BRB model, composed of retinal microvessel endothelial cells, to ascertain the MCR subtype(s) mediating $\alpha$-MSH's antihyperpermeability in the endothelial cells.

\section{Materials and Methods}

Animals

One hundred and thirty Sprague Dawley male rats (8 weeks of age, body weight $200 \sim 220 \mathrm{~g}$ ) were purchased from the Chinese Academy of Military Medical Sciences (Beijing, China). The rats were fed ad lib with food and water, and raised at $22 \sim 25{ }^{\circ} \mathrm{C}$ with relative humidity of $40 \sim 70 \%$ under $12 \mathrm{~h} \mathrm{light-dark}$ cyclic illumination. All experimental procedures were evaluated and approved by the Institutional Animal Care and Use Committee of Tianjin Medical University (Permit Number: SYXK 2009-0001), and were in accordance with the Guide for the Care and Use of Laboratory Animals of the National Institutes of Health.

\section{Diabetic induction}

The rats were randomly divided into normal $(n=40)$, normal $+\alpha-M S H(n=10)$, diabetes mellitus (DM, $n=40)$, and DM $+\alpha-$ MSH groups $(n=40)$. The rats in the DM and DM $+\alpha$-MSH groups were injected through tail vein with STZ at $45 \mathrm{mg} / \mathrm{kg}$ (2\% in sodium citrate buffer, pH 4.5, AMRESCO LLC, Solon, OH, USA) to induce diabetes. Equal volume of sodium citrate buffer was intravenously injected into the rats in the normal and normal $+\alpha$-MSH groups. Blood glucose levels were measured at $72 \mathrm{~h}$ following the intravenous injection, and the rats with the blood glucose levels higher than $16.7 \mathrm{mM}$ were deemed diabetic and included in subsequent experiments. Water intake and body weight of all experimental animals were monitored on a daily and weekly basis, respectively. The blood glucose levels were measured again at W 5 after the intravenous injection of STZ or sodium citrate buffer.

\section{Intravitreal injections}

At $\mathrm{W} 1$ and 3 after the intravenous injection, the rats in the normal $+\alpha-\mathrm{MSH}$ and DM $+\alpha-\mathrm{MSH}$ groups were intravitreally injected with $3 \mu \mathrm{l} \alpha$-MSH $(3.3 \mu \mathrm{g} / \mu \mathrm{l}$ in sterilized normal saline, Calbiochem in EMD Millipore, Billerica, MA, USA), and the rats in the DM and normal groups were injected with the same volume of normal saline. In a previous study, the intravitreal administration of $\alpha$-MSH at this dosage (10 $\mu$ g in 3 $\mu \mathrm{l}$ ) and frequency (at W1 and W3 after the intravenous injection) had been shown to effectively normalize oxidative stress, inhibit apoptosis, improve vascular and parenchymal ultrastructures, and correct aberrant expression of pro-inflammatory factors in retinas of STZ-induced diabetic rats [17], therefore, in the current study, the identical regime of $\alpha$-MSH was applied. Briefly, the rats were systemically anesthetized with an intraperitoneal injection of $10 \%$ chloral hydrate $(0.3 \mathrm{ml} / 0.1 \mathrm{~kg})$, the pupils dilated with tropicamide, and the eyes locally anesthetized with oxybuprocaine hydrochloride. The rats were then injected unilaterally (right eyes) at $2 \mathrm{~mm}$ posterior to limbus by a 30-gauge needle mounted on a Hamilton syringe (SigmaAldrich, St. Louis, MO, USA). The needle was kept in vitreous cavity for $15 \mathrm{~s}$, and then gently withdrawn to avoid leakage of injected solution. Ofloxacin eye drop was applied after injection to prevent infection.

\section{Evans blue assay}

At W 5 after the intravenous injection, an Evans blue assay was performed in the rats from normal, $\mathrm{DM}$, and DM $+\alpha-\mathrm{MSH}$ groups as described in the literature [18-20]. Specifically, Evans blue dye (30 mg / $\mathrm{ml}$, dissolved in normal saline and filtered, Sigma-Aldrich, St. Louis, MO, USA) was injected into rat tail veins at $45 \mathrm{mg} / \mathrm{kg}$. After the dye had been circulating for $2 \mathrm{~h}, 3$ rats were killed in each group, and retina whole mounts were prepared to examine retinal vasculature morphology and vascular leakage under a fluorescence microscope (BX51, Olympus Optical Co. Ltd., Tokyo, Japan) using a Texas Red filter. On the other hand, blood samples ( $2 \mathrm{ml}, 8$ rats / group) were collected from angular veins, and stored at $4{ }^{\circ} \mathrm{C}$ in heparin-coated tubes. The rats were then perfused thoroughly via left ventricle with pre-warmed sodium citrate buffer ( $\mathrm{pH} 3.5)$ to avoid vessel constriction. The retinas were isolated and stored at $-80^{\circ} \mathrm{C}$. 


\section{Cellular Physiology Cell Physiol Biochem 2018;45:505-522 \begin{tabular}{l|l|l} 
DOI: 10.1159/000487029 & Ond Biochemistry Published online: January 31, 2018 & $\begin{array}{l}\text { O 2018 The Author(s). Published by S. Karger AG, Basel } \\
\text { www.karger.com/cpb }\end{array}$
\end{tabular}}

Cai et al.: A-MSH Protects Early Diabetic Retina from Vascular Leakage

One milliliter of the blood sample was centrifuged at 12, $000 \mathrm{rpm}$ at room temperature for $20 \mathrm{~min}$. The plasma in the upper layer was collected and diluted 100 fold with formamide. The Evans blue dye was dissolved in formamide at following concentrations: $50,000,25,000,10,000,5,000,1,000,500,250$, 125 , and $0 \mathrm{ng} / \mathrm{ml}$, to generate a standard curve. The standard curve served as both positive and negative controls. Then $60 \mu \mathrm{l}$ of diluted blood samples and standard curve solutions were added to a 96-well plate. The absorbance at $620 \mathrm{~nm}$ with correction at $740 \mathrm{~nm}$ was measured by an Infinite 200 PRO Multimode Microplate Reader (Tecan Group Ltd., Männedorf, Switzerland). The blood concentration of Evans blue dye was calculated based on the standard curve.

Each retina sample was incubated in an oven at $37^{\circ} \mathrm{C}$ for $5 \mathrm{~h}$, and retina dry weight was recorded. Then the retinas were incubated at $70^{\circ} \mathrm{C}$ for $18 \mathrm{~h}$ in $150 \mu \mathrm{l}$ formamide. The retinal sample extracts were applied to EMD Millipore Amicon Ultra-0.5 Centrifugal Filter Units (NMWL 30000, Fisher Scientific, Pittsburgh, PA, USA), and centrifuged at $3,000 \mathrm{~g}, 4^{\circ} \mathrm{C}$ for $90 \mathrm{~min}$. The filtrates, containing molecules lower than $30 \mathrm{kD}$, were collected. The concentration of Evans blue dye in the filtrate was calculated as described above. The Evans blue permeability in retinal sample was calculated according to the following formula: Permeability [ $\mu \mathrm{l} /$ $(\mathrm{g} \bullet \mathrm{h})]=[$ Evans blue content in retina $(\mu \mathrm{g}) /$ retina dry weight $(\mathrm{g})] /$ [time-averaged Evans blue concentration in blood $(\mu \mathrm{g} / \mu \mathrm{l}) \times$ circulating time $(\mathrm{h})]$.

\section{Transmission electron microscopy}

The eyes from the animals of normal, DM, and DM $+\alpha$-MSH groups ( $\mathrm{n}=5 /$ group) were collected for transmission electron microscopy. Briefly, the eye balls were fixed in pre-chilled $2.5 \%$ glutaraldehyde solution (pH 7.4, Sigma-Aldrich, St. Louis, MO, USA) and 1\% osmium tetroxide solution (Sigma-Aldrich, St. Louis, MO, USA), and dehydrated in gradient ethanol. The eyes were treated with epoxy propane, embedded in 812 resin (Electron Microscopy Sciences, Hatfield, PA, USA), and processed for ultrathin sections $( \pm 50 \mathrm{~nm}$ / section). The sections were stained with uranyl acetate and lead citrate, observed under a Hitachi-7500 transmission electron microscope (Hitachi, Tokyo, Japan), and photographed by the MegaView digital electron microscopy system (Olympus Soft Imaging Solutions Corp., Lakewood, CO, USA).

\section{Electroretinogram}

At W 5 following the intravenous injection, the rats in the normal $(\mathrm{n}=16)$, normal $+\alpha-\mathrm{MSH}(\mathrm{n}=$ $10)$, DM $(n=16)$, and DM + $\alpha$-MSH groups $(n=16)$ were subjected to scotopic electroretinogram (ERG) analyses. Briefly, the animals were dark-accommodated for $16 \mathrm{~h}$ before systemic anesthesia was induced by an intraperitoneal injection of chloral hydrate $(0.25 \mathrm{ml} / 0.1 \mathrm{~kg})$. The anesthetized rats were fixed on a stage in a supine position. The pupils were dilated with $2.5 \%$ phenylephrine and $1 \%$ tropicamide. Platinum needle electrodes were placed on both corneas. A reference electrode was positioned in the skin behind ear and a ground electrode in the skin close to tail. The full-field dark-adapted ERGs elicited by white flash lights with luminance of $0.01,3.0$, and $30.0 \mathrm{~cd}^{*} \mathrm{~s} / \mathrm{m}^{2}$ were recorded by a RetiMINER-Visual Electrophysiology (ChongQing IRC Medical Equipment, Chongqing, China) following the manufacturer's instructions.

\section{Hematoxylin and eosin staining}

At the end of study, the eye balls of rats in normal $(n=8)$, normal $+\alpha-M S H(n=10), D M(n=8)$, and DM $+\alpha$-MSH groups $(n=8)$ were fixed with $4 \%$ paraformaldehyde for $24 \mathrm{~h}$, embedded in paraffin, and serially sectioned ( $3 \mu \mathrm{m}$ thick). Eight sections from the comparable position of each eye ball were selected and stained with hematoxylin and eosin (H\&E). The stained sections were pictured under the bright field of a BX51 microscope (Olympus Optical Co. Ltd., Tokyo, Japan) under identical magnification while keeping the whole retinal layers within one picture. The thicknesses of photoreceptor outer segment (OS), outer nuclear layer (ONL), outer plexiform layer (OPL), inner nuclear layer (INL), inner plexiform layer (IPL), and total retina were measured using a cellSens Standard electronic system (Olympus Optical Co. Ltd., Tokyo, Japan).

\section{Retinal microvessel endothelial cells and their treatment with high glucose}

A simian retinal microvessel endothelial cell line RF/6A was purchased from the Chinese Academy of Science (Shanghai, China) and maintained in complete culture media consisting of RPMI 1640 (glucose at 11.1 mM; Thermo Fisher Scientific, Waltham, MA, USA), 10\% fetal bovine serum (Thermo Fisher Scientific, Waltham, MA, USA), $100 \mathrm{U} / \mathrm{ml}$ penicillin, $100 \mu \mathrm{g} / \mathrm{ml}$ streptomycin (Thermo Fisher Scientific, Waltham, MA, USA), and $2 \mathrm{mM} \mathrm{L-glutamine} \mathrm{(Thermo} \mathrm{Fisher} \mathrm{Scientific,} \mathrm{Waltham,} \mathrm{MA,} \mathrm{USA)} \mathrm{under} 37{ }^{\circ} \mathrm{C}$ and $5 \% \mathrm{CO}_{2}$ in a 
humidified incubator. The RF6A cells were seeded at a density of $2 \mathrm{X} 10^{5} /$ well in the complete culture media in a 24-well plate, and were divided into normal and high glucose (HG) groups ( $n=6$ / group). On the following day, the cells in the normal group were incubated with plain RPMI1640 media, whereas the HG group was stimulated with the RMPI 1640 media containing $27 \mathrm{mM}$ glucose, the concentration corresponding to the averaged blood glucose level in the diabetic rats. Eight hours later, both groups of cells were collected for gene expression analyses.

Table 1. The PCR primers in this study, Note: the qPCR primers of rat VEGF gene were designed according to the common sequence of its 6 alternatively spliced transcripts encoding de facto proteins

\begin{tabular}{|c|c|c|c|c|}
\hline Primers & Gene ID & Species & Purpose & Primer sequences \\
\hline $\begin{array}{l}\text { ICAM-1 } \\
\text { forward }\end{array}$ & NM_012967.1 & Rat & qPCR & CGGGAGATGAATGGTACCTACAA \\
\hline reverse & & & & TGCAGTCCCTGGTGATACTC \\
\hline $\begin{array}{l}\text { TNF- } \alpha \\
\text { forward }\end{array}$ & NM_012675.3 & Rat & qPCR & TGATCGGTCCCAACAAGGA \\
\hline reverse & & & & GGGTCTGGGCCATGGAA \\
\hline $\begin{array}{l}\text { occludin } \\
\text { forward }\end{array}$ & NM_031329.2 & Rat & qPCR & GGCGGAGAGATGCACGTT \\
\hline reverse & & & & GAATTTCGTCTTCCGGGTAAAA \\
\hline & $\begin{array}{c}\text { NM_031836.3, } \\
\text { NM_001110333.2, }\end{array}$ & & & \\
\hline $\begin{array}{l}\text { VEGF } \\
\text { forward }\end{array}$ & $\begin{array}{l}\text { NM_001110334.2, } \\
\text { NM_001287111.1 }\end{array}$ & Rat & qPCR & GGCTCGCGGGATTGC \\
\hline & NM_001287113.1 & & & \\
\hline & NM_001287114.1 & & & \\
\hline Reverse & & & & GCGCAGACCACGGCTACT \\
\hline $\begin{array}{l}18 \mathrm{~S} \\
\text { forward }\end{array}$ & NR_046237.1 & Rat & qPCR & TGATTAAGTCCCTGCCCTTTGT \\
\hline reverse & & & & GATCCGAGGGCCTCACTAAAC \\
\hline $\begin{array}{l}\text { MC3R } \\
\text { forward }\end{array}$ & XM_001091108.2 & Monkey & qPCR & CATGTTCTTCGCCATGATGCT \\
\hline reverse & & & & GCCGCGCAAAGAGGAA \\
\hline $\begin{array}{l}\text { MC4R } \\
\text { forward }\end{array}$ & XM_001088600.3 & Monkey & qPCR & CGTGGGATGCACGCTTCT \\
\hline reverse & & & & GGCATTGCTGTGCAGTCTGT \\
\hline $\begin{array}{l}\text { MC5R } \\
\text { forward }\end{array}$ & NM_001193897.1 & Monkey & qPCR & CCGGCATCTGGGCTTTC \\
\hline reverse & & & & ACGTAGGTGGACTCGGAGTACAG \\
\hline $\begin{array}{l}\text { MC1R } \\
\text { forward }\end{array}$ & NM_001164589.1 & Monkey & $\begin{array}{l}\text { detectio } \\
\mathrm{n}\end{array}$ & AGGGCTCCCAGAGAAGACTC \\
\hline reverse & & & & ATGGAGATGTAGCGGTCCAC \\
\hline $\begin{array}{l}\text { MC3R } \\
\text { forward }\end{array}$ & XM_001091108.2 & Monkey & $\begin{array}{l}\text { detectio } \\
\mathrm{n}\end{array}$ & АCTCCATGACCTGCATCTCC \\
\hline reverse & & & & AGATGCAGTAGGGGTTGGTG \\
\hline $\begin{array}{l}\text { MC4R } \\
\text { forward }\end{array}$ & XM_001088600.3 & Monkey & $\begin{array}{l}\text { detectio } \\
\mathrm{n}\end{array}$ & CCAGTGAGTCCCTTGGAAAA \\
\hline reverse & & & & CCAACCCGCTTAACTGTCAT \\
\hline $\begin{array}{l}\text { MC5R } \\
\text { forward }\end{array}$ & NM_001193897.1 & Monkey & $\begin{array}{l}\text { detectio } \\
\mathrm{n}\end{array}$ & TGATAGCAGACGCCTTTGTG \\
\hline reverse & & & & TTCTGAGGGCAAGAAAGCAT \\
\hline
\end{tabular}




\section{Cellular Physiology Cell Physiol Biochem 2018;45:505-522 \begin{tabular}{ll|l} 
and Biochemistry Published online: January 31, 2018 & $\begin{array}{l}\text { (C) } 2018 \text { The Author(s). Published by S. Karger AG, Basel } \\
\text { www.karger.com/cpb }\end{array}$
\end{tabular}}

Cai et al.: A-MSH Protects Early Diabetic Retina from Vascular Leakage

\section{Total RNA extraction and reverse transcription}

The retinas from normal, DM, and DM $+\alpha$-MSH groups of rats $(\mathrm{n}=8$ / group) were isolated at W 5 following the intravenous injection. The total RNAs from either the rat retinas or the collected RF6A cells were extracted using a GeneJET RNA Extraction Kit (Thermo Fisher Scientific, Waltham, MA, USA). The concentration and purity of the total RNAs were examined by a Nanodrop 2000 (Thermo Fisher Scientific, Waltham, MA, USA). After a thorough digestion with DNase I at $37{ }^{\circ} \mathrm{C}$ for $30 \mathrm{~min}, 450 \mathrm{ng}$ of the total RNA were reverse transcribed using random hexamer primers and reagents in a RevertAid cDNA synthesis Kit (Thermo Fisher Scientific, Waltham, MA, USA) according to manufacturer's protocol.

\section{Regular PCR}

The expression of melanocortin receptor 1, 3, 4, 5 (MC1, 3, 4, 5R) in the HG-treated RF6A cells were examined via Regular PCR. The PCR was conducted in a GeneAmp PCR System 2400 (PerkinElmer, Waltham, MA, USA) using GoTaq Green 2X Master Mix (Thermo Fisher Scientific, Waltham, MA, USA), $2 \mu$ l cDNA template from the HG-treated RF6A cells, and specific detection primers for monkey MCR genes (Table 1). The PCRs using water as templates were included as negative controls. The regular PCR reaction initiated with a 5 -min denaturation at $94{ }^{\circ} \mathrm{C}$, followed by 35 cycles of denaturation at $94{ }^{\circ} \mathrm{C}$ for $30 \mathrm{~s}$, annealing at 60 ${ }^{\circ} \mathrm{C}$ for $30 \mathrm{~s}$, and extension at $72{ }^{\circ} \mathrm{C}$ for $30 \mathrm{~s}$, with a final extension at $72{ }^{\circ} \mathrm{C}$ for $7 \mathrm{~min}$. The PCR products were visualized on a $1 \%$ agarose gel.

\section{Quantitative real-time PCR}

The expression levels of intercellular adhesion molecule-1 (ICAM-1), tumor necrosis factor- $\alpha$ (TNF- $\alpha$ ), occludin, VEGF, MC3R, MC4R, and MC5R were examined using quantitative real-time PCR (qPCR) in a HT7900 Real-Time PCR System (Applied Biosystem, Foster City, CA, USA). The cDNA content of each target gene was normalized to the internal standard $18 \mathrm{~S}$ ribosomal RNA gene (18S rRNA). The reaction mixture was composed of $3 \mu \mathrm{l}$ cDNA template, gene-specific qPCR primers (Table 1), and $5 \mu$ l SYBR Green FastStart 2X Master Mix (Roche, Branford, CT, USA). One microliter cDNA from each sample was pooled, seriallydiluted, and used as templates to generate a standard curve between Ct values of each gene and logarithms of cDNA template concentrations. The standard curves demonstrated similar priming efficiencies between each target gene and 18S rRNA gene. The standard curves also served as positive controls for qPCR, and the reactions using water as template served as negative controls. The qPCR program consisted of preincubation at $50{ }^{\circ} \mathrm{C}$ for $2 \mathrm{~min}$, denaturation at $95{ }^{\circ} \mathrm{C}$ for $10 \mathrm{~min}, 40$ cycles of denaturation at $95{ }^{\circ} \mathrm{C}$ for $15 \mathrm{~s}$ and extension at $60^{\circ} \mathrm{C}$ for $1 \mathrm{~min}$. A dissociation stage was added to check amplicon specificity. The relative expression levels of target genes were analyzed using a comparative threshold cycle $\left(2^{-\Delta \Delta C t}\right)$ method.

\section{Total protein extraction and concentration determination}

The total protein was extracted from the retinas of normal, DM, and DM $+\alpha-M S H$ groups ( $n=8 /$ group) by a Tissue Protein Extraction Kit (CWBIO, Beijing, China), and the protein concentration was determined using a Bicinchoninic Acid (BCA) Protein Assay Kit (CWBIO, Beijing, China). Bovine serum albumin standard ( $2 \mathrm{mg} / \mathrm{ml}$, CWBIO, Beijing, China) was serially diluted to generate a standard curve and serve as the positive control for protein quantification. The diluent was included as the negative control. Then $25 \mu \mathrm{l}$ of standards and the 5 -fold diluted protein samples were incubated with BCA reagents at $37^{\circ} \mathrm{C}$ for $30 \mathrm{~min}$. The absorbance at $562 \mathrm{~nm}$ was measured. The protein concentration was calculated according to the standard curve.

\section{Western blots}

The protein samples from the retinas of normal, DM, and DM $+\alpha-M S H$ groups of rats ( $\mathrm{n}=8 /$ group) were analyzed by Western blots as previously described [21, 22]. Briefly, $50 \mu \mathrm{g}$ total proteins from each retina were resolved in a 10\% sodium dodecyl sulfate polyacrylamide gel, and transferred to a polyvinylidene difluoride membrane. The blots were washed, blocked with 5\% non-fat dry milk, and incubated with rabbit polyclonal antibody to ICAM-1 (1:1000 dilution) and rabbit monoclonal antibody to Occludin (1:50000 dilution) (Abcam, Cambridge, MA, USA) at $4{ }^{\circ} \mathrm{C}$ overnight. On the next day, the blots were washed and incubated with goat anti-rabbit horseradish peroxidase-conjugated secondary antibody (1:2000 dilution, Abcam, Cambridge, MA, USA) at room temperature for $2 \mathrm{~h}$. The protein signals were visualized with enhanced Chemiluminescence plus reagents (Amersham Biosciences, Piscataway, NJ, USA), and imaged using a Multispectral Imaging System (Biospectrum AC Chemi HR 410, UVP, LLC, Upland, CA, USA). The blots were 


\section{Cellular Physiology Cell Physiol Biochem 2018;45:505-522 \begin{tabular}{ll|l} 
DOI: 10.1159/000487029 & O 2018 The Author(s). Published by S. Karger AG, Basel \\
www.karger.com/cpb
\end{tabular}}

Cai et al.: A-MSH Protects Early Diabetic Retina from Vascular Leakage

then stripped and probed with a monoclonal antibody to $\beta$-tubulin (1:2000 dilution, BD Biosciences, San Jose, CA, USA) to serve as an internal standard. The optical densities of the target proteins were quantified by Image J (National Institute of Health, Bethesda, MD, USA) and normalized to that of $\beta$-tubulin.

\section{Enzyme-linked immunosorbent assay}

The concentrations of TNF- $\alpha$ and VEGF in the retina total protein samples were determined using the Enzyme-linked immunosorbent assay (ELISA) kits (R\&D Systems, Minneapolis, MN, USA; TNF- $\alpha$ : Cat\# RTA00, VEGF: Cat\# RRV00) according to the manufacturer's protocols. Briefly, a monoclonal antibody specific to target protein was pre-coated on a 96-well microplate. After the target protein in samples bound to the pre-coated antibody, an enzyme-linked polyclonal antibody was added to sandwich the immobilized target protein. Finally, the colorimetric substrates were added for quantification. The standard curves served as the positive controls, whereas the wells containing only diluent were included as the negative controls for the ELISAs. The optical density was measured at $450 \mathrm{~nm}$ with correction at $540 \mathrm{~nm}$ by an Infinite 200 PRO Multimode Microplate Reader (Tecan Group Ltd., Männedorf, Switzerland). The concentrations of target proteins $(\mathrm{pg} / \mathrm{ml})$ in each retina sample were calculated based on the corresponding standard curves, and then normalized to the total protein concentration $(\mu \mathrm{g} / \mu \mathrm{l})$ in that sample.

\section{Transendothelial electrical resistance}

The RF6A cells were seeded at $5 \times 10^{4} /$ well on the culture inserts $(0.4 \mu \mathrm{m}$ pore size and $6.5 \mathrm{~mm}$ diameter; Corning, Sigma-Aldrich, St. Louis, MO, USA) in the 24-well plates. The cells were maintained in the complete culture media, with $300 \mu \mathrm{l}$ in the inserts and $1 \mathrm{ml}$ in the lower chamber. The media were changed every $2 \mathrm{~d}$. The cells reached confluence in about $6 \mathrm{~d}$.

Then the cells were divided into 6 groups. In addition to the normal, HG, and $\alpha$-MSH + HG groups, based on the expression profiling of MCRs in RF6A cells, a pan MCR blocker agouti-signaling protein (ASIP, Abnova, Taipei, Taiwan), a MC3R and MC4R blocker agouti-related protein (AGRP, Phoenix Pharmaceuticals, Burlingame, CA), and a specific MC4R blocker HS024 (TOCRIS Biosciences, Minneapolis, MN, USA) were added to the cells treated with $\alpha$-MSH $+\mathrm{HG}$, constituting another 3 groups. In this experiment, the normal and HG groups were pre-treated with plain RPMI 1640; the other 4 groups were pre-treated with $0.1 \mu \mathrm{M}$ $\alpha$-MSH, $0.1 \mu \mathrm{M} \alpha$-MSH $+10 \mathrm{nM}$ ASIP, $0.1 \mu \mathrm{M} \alpha-\mathrm{MSH}+0.5 \mu \mathrm{M}$ AGRP, and $0.1 \mu \mathrm{M} \alpha-\mathrm{MSH}+0.1 \mu \mathrm{M}$ HS024, respectively, for $30 \mathrm{~min}$. Subsequently, all the HG-related groups were stimulated with $27 \mathrm{mM} \mathrm{HG}$ for $8 \mathrm{~h}$ at the presence of $\alpha-\mathrm{MSH}$ and the corresponding blockers, whereas the norm was maintained in plain RPMI 1640 media. The concentrations of $\alpha$-MSH, MCR blockers, and HG were selected according to the previous studies by us [23] and others [24]. The culture inserts without cells subserved the background.

After the $8 \mathrm{~h}$ treatment, the culture inserts were transferred into an Endohm chamber, and the transendothelial electrical resistance (TEER) was measured using an endothelial volt/ohm meter (EVOM², World Precision Instruments, Sarasota, FL, USA) as described elsewhere [25]. The net TEER was obtained after subtraction of the background value, and expressed as percentage of normal control.

\section{Retinal microvessel endothelial cell monolayer permeability}

The RF6A cell monolayer was prepared in the culture inserts, and treated with $\alpha$-MSH, MCR blockers, and HG as described above. Following the $8 \mathrm{~h}$ treatment, the cell monolayer permeability was examined as described previously with minor modifications [26]. Briefly, the cell-bearing inserts were transferred to a new 24-well plate with $600 \mu \mathrm{l}$ plain RPMI 1640 in each well. The media in the inserts were replaced with $200 \mu$ l plain RPMI containing $0.2 \mathrm{mg} / \mathrm{ml}$ fluorescein isothiocyanate (FITC)-Dextran (average molecular weight 4000; Sigma-Aldrich, St. Louis, MO, USA). The cells were incubated at $37^{\circ} \mathrm{C}$ for $1 \mathrm{~h}$, the wells containing merely RPMI 1640 served as the background. The fluorescence intensities of lower chambers were measured at $490 \mathrm{~nm}$ with correction at $530 \mathrm{~nm}$ by an Infinite 200 PRO Multimode Microplate Reader (Tecan Group Ltd., Männedorf, Switzerland), and the fluorescence intensity of the transferred FITC-Dextran was obtained by subtracting the background value, and expressed as percentage of normal control.

\section{Statistics}

Statistical analyses were performed using Statistical Program for Social Sciences 20.0 (IBM SPSS Inc., New York, NY, USA). All data were expressed as Mean \pm SEM. The data were examined by D'Agostino and Pearson omnibus normality test to confirm Gaussian distribution, after which they were examined by 


\section{Cellular Physiology Cell Physiol Biochem 2018;45:505-522

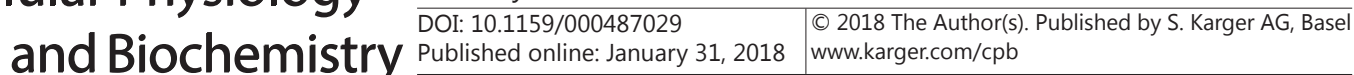

Levene test to confirm homogeneity of variance. Then the differences in physiological parameters between DM and normal rats, and the gene expression levels of MCR receptors in normal and HG-treated retinal endothelial cells were analyzed by Two-way ANOVA followed by Tukey post hoc; other quantitative results were analyzed by One-way ANOVA followed by Tukey post hoc. A $P$ value less than 0.05 was considered significant.

\section{Results}

Intravenous injection of STZ induces diabetic phenotypes in rats

At D 3 and $\mathrm{W} 1$ to 5 following the intravenous injection, the body weight of normal rats significantly increased along with time $\left(F_{\text {time }}=12.930, P=0.000\right)$, whereas that of DM rats did not vary dramatically (Table 2 ). The body weight of diabetic rats was significantly lower than normal counterparts at each time points examined (Table 2 , all $P<0.001$, DM vs normal).

At D 3 and W 5 after the intravenous injection, the blood glucose levels of normal rats were $(6.93 \pm 1.12) \mathrm{mM}$ and $(5.08 \pm 1.13) \mathrm{mM}$, respectively; whereas those in DM rats surged to $(29.69 \pm 4.77) \mathrm{mM}$ and $(24.64 \pm 2.72) \mathrm{mM}$, respectively (both $P<0.001$, DM vs normal).

At $\mathrm{W} 4$ following the intravenous injection, the averaged daily water consumption of normal rats was $62.27 \pm 23.95 \mathrm{ml}$, the diabetics consumed $242.76 \pm 51.75 \mathrm{ml}$ water each day. These physiological parameters suggest that single intravenous injection of STZ can induce the diabetic phenotypes, including reduced body weight, hyperglycemia, and polydipsia.

\section{$\alpha$-MSH protects early diabetic retina against BRB breakdown and vascular leakage}

At W 5 after the intravenous injection of sodium citrate buffer, normal retinal vessels were evenly distributed with smooth vessel walls and regular trajectories as revealed by the intravenously injected Evan blue dye under a fluorescence microscope. No leakage of the blue dye was observed in normal retinas (Fig. 1A). In contrast, diabetic retinal vessels were tortuous and with uneven calibers, and the dye leakage was frequently observed around macro- and microvessels (Fig. 1B). Importantly, the trajectories and distribution of the vessels in $\alpha$-MSH-treated diabetic retinas were similar to those in normal retinas, and the leakage of the blue dye was not observed in this group of retinas (Fig. 1C), indicating that $\alpha$-MSH might alleviate BRB breakdown and vascular leakage in early diabetic retina.

Another assay was employed to quantify the permeability of the intravenously-injected blue dye in retina. The results demonstrated that the permeability of blue dye in normal retinas was $3.10 \pm 1.13 \mu \mathrm{l} /(\mathrm{g} \bullet \mathrm{h})$, which was boosted 3.24 fold in diabetic ones, being $10.04 \pm$ $8.18 \mu \mathrm{l} /(\mathrm{g} \bullet \mathrm{h}$ ) (Fig. 1D, $P<0.05$, normal vs DM). Intravitreal injections of $\alpha$-MSH significantly reduced the blue dye permeability in diabetic retinas to the level similar to normal controls (Fig. 1D, $P<0.05$, DM vs $\alpha-\mathrm{MSH}+\mathrm{DM} ; P=0.735$, normal vs $\alpha-\mathrm{MSH}+\mathrm{DM}$ ). The result of quantified dye permeability was consistent with retinal vasculature morphology, confirming $\alpha$-MSH's protection on the intactness of BRB and retinal vessels during early diabetes.

Table 2. The body weight of normal and diabetic rats. Note: \# indicates $\mathrm{P}<0.001$, normal vs DM

\begin{tabular}{lccccccc}
\hline Group & \multicolumn{7}{c}{ Body weight (g) } \\
s & D 0 & D 3 & W 1 & W 2 & W 3 & W 4 & W 5 \\
\hline Norm & $281.36 \pm 9.8$ & $317.82 \pm 14.7$ & $365.55 \pm 24.8$ & $404.45 \pm 34.2$ & $426.18 \pm 37.9$ & $444.18 \pm 35.3$ & $471.00 \pm 43.8$ \\
al & 4 & $8^{\#}$ & $6^{\#}$ & $3^{\#}$ & $4^{\#}$ & $3^{\#}$ & $6^{\#}$ \\
& $279.50 \pm 12$. & $285.33 \pm 12.0$ & $299.86 \pm 24.9$ & $307.07 \pm 31.1$ & $296.04 \pm 40.7$ & $309.67 \pm 43.6$ & $323.52 \pm 43.3$ \\
DM & 51 & 0 & 8 & 3 & 6 & 5 & 1 \\
\end{tabular}


Fig. 1. Intravitreal injections of $\alpha$-MSH protected diabetic retinas from BRB breakdown and vascular leakage. After tail vein injection of Evans blue dye, the morphology of retinal vasculature in the normal (A), DM (B), and $\alpha$-MSH-treated DM (C) rats were examined under the red filter of a fluorescence microscope. The white arrow in (B) indicates the leakage of the blue dye from the diabetic retinal vessels. The permeability of the blue dye in retina was quantified through Evans blue assay and compared among the 3 experimental groups (D). ${ }^{*} \mathrm{P}<0.05$. Scale bar $=$ $100 \mu \mathrm{m}$.

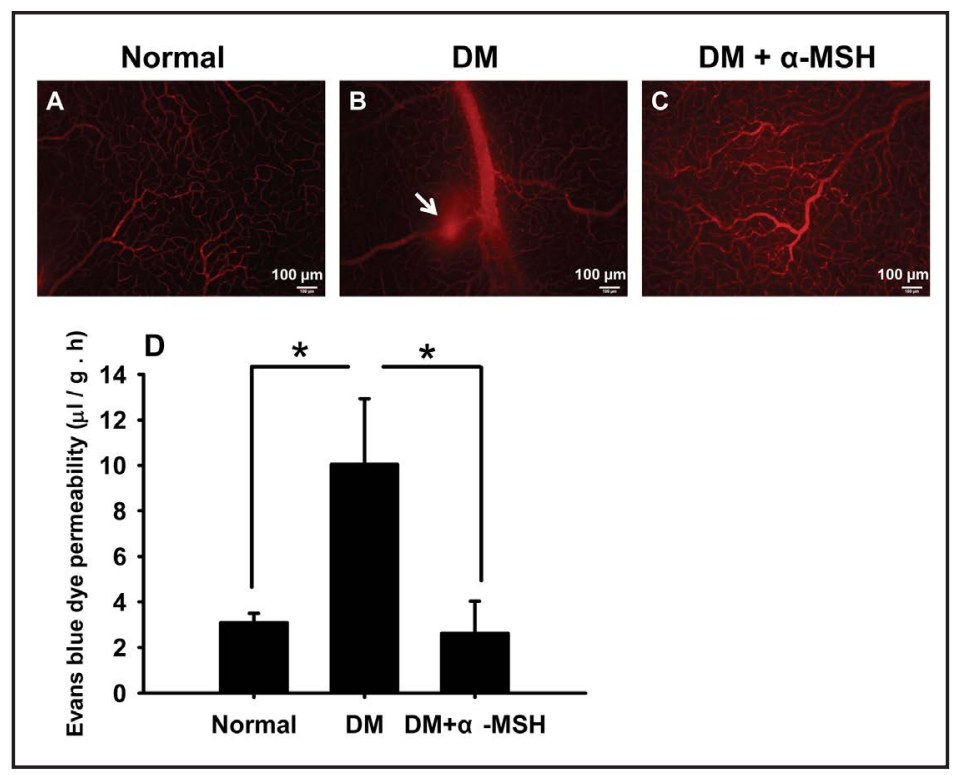

$\alpha$-MSH improves ultrastructures of choroidal and retinal vessels in early diabetic retina

At W 5 after the intravenous injection, transmission electron microscopy was employed to examine ultrastructural changes in choroidal and retinal vessels. The choroidal and retinal capillaries in normal retinas had clear lumens, in which passing erythrocytes were observed (Fig. 2A, B). The basement membranes of normal choroidal and retinal capillaries were intact, the collagen fibers outside the basement membrane were well-organized (Fig. 2A, B). In diabetic retinas, the choroidal capillaries exhibited the multi-layered, onion skinlike basement membranes, and the slightly swelled vascular endothelial cells attached to one side of the lumen. The intercellular space was expanded in retinal pigment epithelia (RPE), and vacuolar degeneration was observed in this tissue (Fig. 2C). In addition, the swelled and deformed microvessel endothelial cells aggregated with erythrocytes, obstructing microvessel lumens and leading to retinal capillary stenosis (Fig. 2D). These ultrastructural changes in diabetic retinas suggest that the damage in outer BRB (mainly composed of RPE cells) and inner BRB (mainly composed of retinal microvessel endothelial cells) [27, 28] has already occurred at W 5 after diabetic onset, thereby forming a morphological basis for diabetes-induced retinal vascular leakage. More importantly, the ultrastructures of choroidal and retinal microvessels in the $\alpha$-MSH-treated diabetic retinas were substantially improved and similar to those in normal retinas (Fig. 2E, F), implicating $\alpha$-MSH's protection of early diabetic retina from BRB breakdown.

\section{$\alpha$-MSH ameliorates electrophysiological functional defects in early diabetic retina}

At W 5 following the intravenous injection of STZ or sodium citrate buffer, the retinal functions of the experimental animals were evaluated by ERG. Since rodent photoreceptors are rod-dominant, only scotopic full-field ERG responses were recorded. Upon the stimulus luminance of $3.0 \mathrm{~cd} * \mathrm{~s} / \mathrm{m}^{2}$, the a wave implicit time of the normal rats was $20.67 \pm 1.48 \mathrm{~ms}$. It was significantly prolonged to $23.47 \pm 3.43 \mathrm{~ms}$ in the diabetics (Fig. 3E, normal vs DM, $P$ $<0.01$ ), and was recovered to the normal range by intravitreal injections of $\alpha$-MSH (Fig. 3E, $P<0.05$, DM vs DM $+\alpha-\mathrm{MSH} ; P=0.951$, normal vs $\mathrm{DM}+\alpha-\mathrm{MSH})$. Moreover, the amplitudes of a wave and $\mathrm{b}$ wave of the normal rats were $93.17 \pm 48.14 \mu \mathrm{V}$ and $191.85 \pm 81.79 \mu \mathrm{V}$, respectively, under the stimulation of $3.0 \mathrm{~cd}{ }^{*} \mathrm{~s} / \mathrm{m}^{2}$ flash light. By contrast, these amplitudes shrank about $1 / 3$ in the diabetic rats (Fig. 3F, G, both $P<0.05$, Normal vs DM), and were boosted to the levels similar to those in the norms by intravitreal administration of $\alpha$-MSH (Fig. 3F, G, both $P<0.05$, DM vs DM $+\alpha-\mathrm{MSH}$; Normal vs $\mathrm{DM}+\alpha-\mathrm{MSH}, P=0.763$ for a wave, $P=0.712$ for $\mathrm{b}$ wave). The a wave implicit time and amplitudes of a wave and $\mathrm{b}$ wave upon 
Fig. 2. Intravitreal administrations of $\alpha$-MSH improved vascular ultrastructures in diabetic animals. Transmission electron microscopy revealed the clear lumens and the passing red blood cells in the normal choroidal (A) and retinal (B) microvessels; In diabetic animals, the swelled endothelial cell (white arrow head) adhered to one side of the choroidal microvessel (C) with multi-layered basement membrane (black arrow heads), and the vacuolated degeneration (black arrows) appeared in the RPE; The deformed and swelled endothelial cells (white arrow heads) and the sand-like red blood cell (white arrow) obstructed the lumen of retinal microvessels (D). The morphology of the $\alpha$-MSH-treated choroidal (E) and retinal (F) capillaries was substantially improved and similar to that in the normal rats. Scale bar $=500 \mathrm{~nm}$.

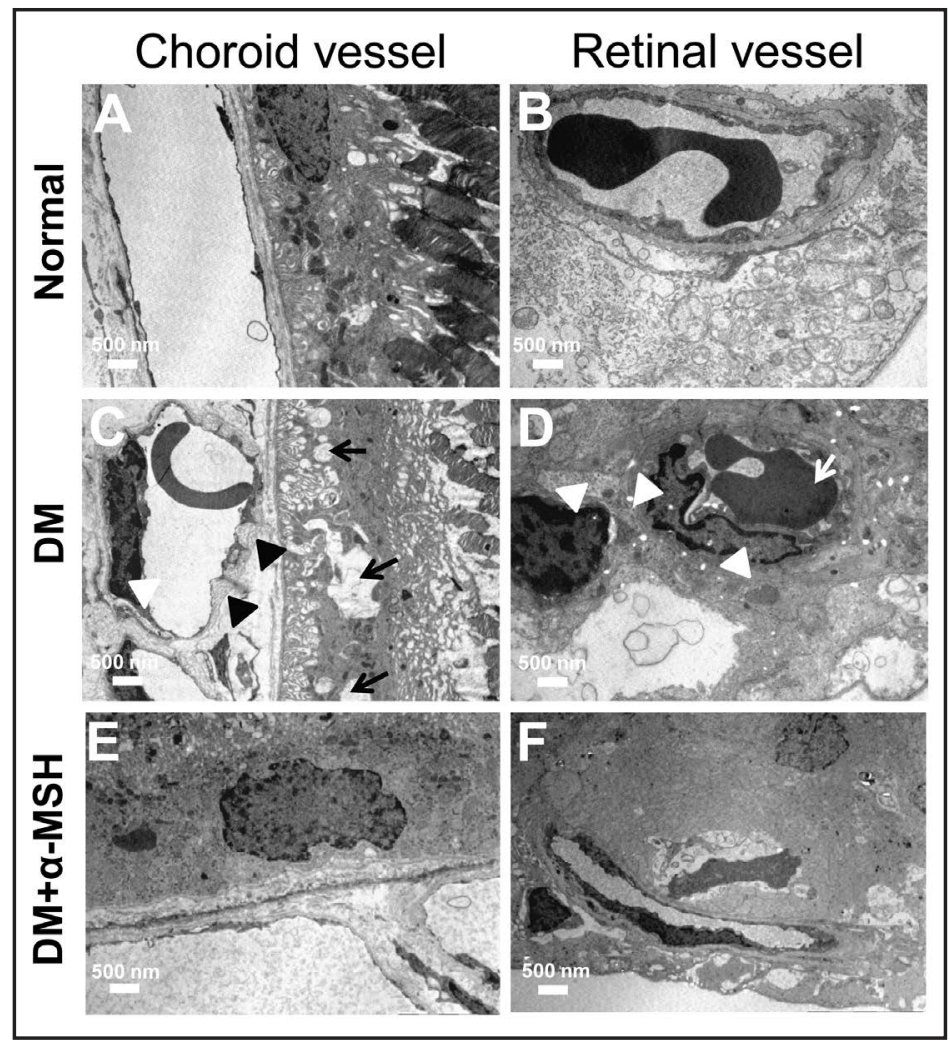

the stimulus of $30.0 \mathrm{~cd} * \mathrm{~s} / \mathrm{m}^{2}$ exhibited similar trends to those upon the $3.0 \mathrm{~cd} / \mathrm{s} / \mathrm{m}^{2}$ stimulus (Fig. 3L, M, N). Other ERG parameters did not show significant changes among the groups. These results suggest that the intravitreal administration of $\alpha$-MSH, at least partially, rescues the electrophysiological functions in early diabetic retina.

In order to test whether intravitreal injections of $\alpha$-MSH could affect the functions of normal retina or not, the ERGs of the normal rats that had received the 2 intravitreal $\alpha$-MSH injections were also recorded. The results showed that there were no significant differences in the above-mentioned parameters, including a wave implicit time, a wave and $\mathrm{b}$ wave amplitudes under both 3.0 and $30.0 \mathrm{~cd} * \mathrm{~s} / \mathrm{m}^{2}$ stimuli, between the normal rats and the normal rats intravitreally injected with $\alpha$-MSH (Fig. 3). These results indicate that intravitreal administration of $\alpha$-MSH may not interfere with the electrophysiological functions in normal retinas.

\section{$\alpha$-MSH increases retinal layer thickness in early diabetic retina}

The effects of $\alpha$-MSH on retinal morphology were assessed by H\&E staining of the serial sections at the comparable position of eye ball. The retina of the normal rats was wellorganized and laminated as expected (Fig. 4A). The retinal structures were still organized in the rats that had been induced diabetic for $5 \mathrm{~W}$, however, the thickness of each layer, including OS, ONL, OPL, INL, and IPL, as well as that of total retina was significantly reduced as compared to the normal counterparts (Fig. 4C, E; all $P<0.001$, Normal vs DM). These results were consistent with the previous reports $[20,29,30]$. More importantly, $\alpha-M S H$ intravitreal administration significantly increased the thickness of all the retinal layers in diabetic retinas (Fig. 4D, E; all $P<0.001$, DM vs DM $+\alpha-\mathrm{MSH}$ ), particularly for OS and OPL, the thickness of which was similar to that in the norms (Fig. 4A, D, E; Normal vs DM $+\alpha-\mathrm{MSH}, P=$ 0.600 for OS; $P=0.712$ for $\mathrm{OPL}$ ). These results suggest that $\alpha$-MSH may protect the rat retina from degeneration under the condition of early diabetes.

The retinas of normal rats intravitreally injected with $\alpha$-MSH were also examined. The overall organization and the thickness of all retinal layers in the retinas of normal $+\alpha-\mathrm{MSH}$ 


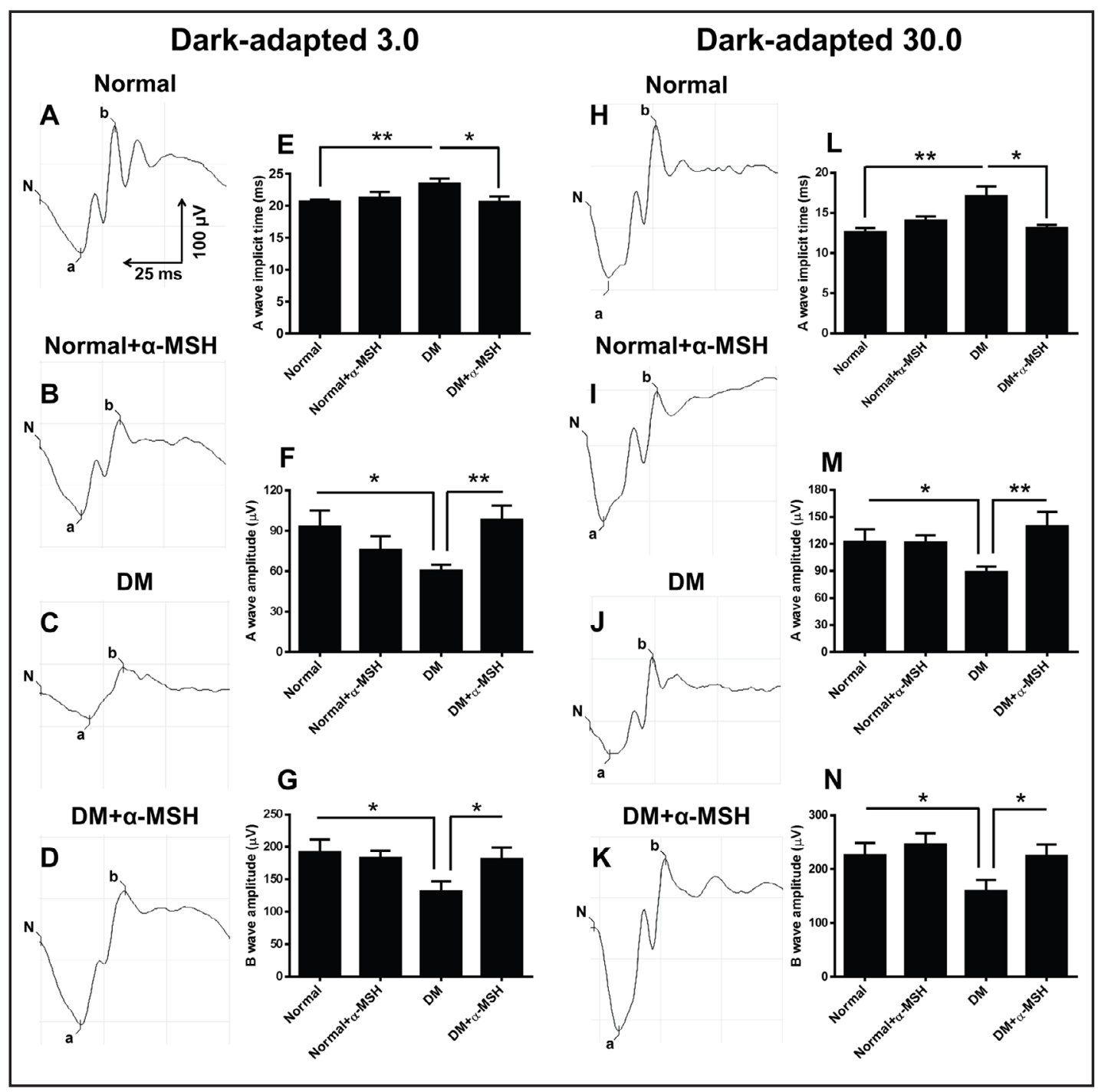

Fig. 3. $\alpha$-MSH alleviated electrophysiological dysfunctions in early diabetic retinas. At W 5 following STZ or sodium citrate injection, the rats were dark-adapted overnight. Upon stimulation of a flash light with $3.0 \mathrm{~cd}^{*} \mathrm{~s} / \mathrm{m}^{2}$, the representative ERG traces of normal (A), normal $+\alpha-\mathrm{MSH}$ (B), DM (C), and DM $+\alpha-\mathrm{MSH}$ (D) rats were shown; the a wave implicit time (E), a wave amplitude (F), and b wave amplitude (G) exhibited significant changes among the experimental groups, and there were not significant differences in these parameters between normal and normal $+\alpha$-MSH groups. Whereas upon a flash light with luminance of $30.0 \mathrm{~cd}^{*} \mathrm{~s} / \mathrm{m}^{2},(\mathrm{H}),(\mathrm{I}),(\mathrm{J})$, and (K)represented the ERGs of normal, normal $+\alpha-\mathrm{MSH}, \mathrm{DM}$, and DM $+\alpha-\mathrm{MSH}$ groups, respectively; the parameters, including a wave implicit time (L), a wave amplitude (M), and b wave amplitude $(\mathrm{N})$, differed significantly among the groups, yet no significant difference was found in these parameters between normal and normal $+\alpha$-MSH groups. ${ }^{*} \mathrm{P}<0.05,{ }^{* *} \mathrm{P}<0.01$.

group were similar to those in the normal counterparts (Fig. 4A, B, E; all $P>0.05$, Normal vs Normal $+\alpha-\mathrm{MSH}$ ), suggesting that intravitreal injections of $\alpha$-MSH did not affect the general morphology of normal retina.

$\alpha$-MSH rectifies aberrant $m R N A$ and protein expression of pro-inflammatory factors and tight junction in early diabetic retina

At W 5 after the intravenous injection, gene expression of the pro-inflammatory factors, such as ICAM- 1 and TNF- $\alpha$, and a tight junction component, Occludin, was examined by qPCR. The results showed that the transcript levels of ICAM-1 and TNF- $\alpha$, were up-regulated 2.70 
Fig. 4. $\alpha-\mathrm{MSH}$ increased thickness of all retinal layers in early diabetic retinas. H\&E staining of retinal sections at the comparable position of eye ball was pictured. The representative images of normal (A), normal $+\alpha$-MSH (B), DM (C), and DM $+\alpha-M S H$ (D) groups were shown. The thickness of all retinal layers, including OS, ONL, OPL, INL, and IPL, as well the thickness of total retina was quantified and shown in (E). No significant difference was found in the thicknesses of all retinal layers between normal

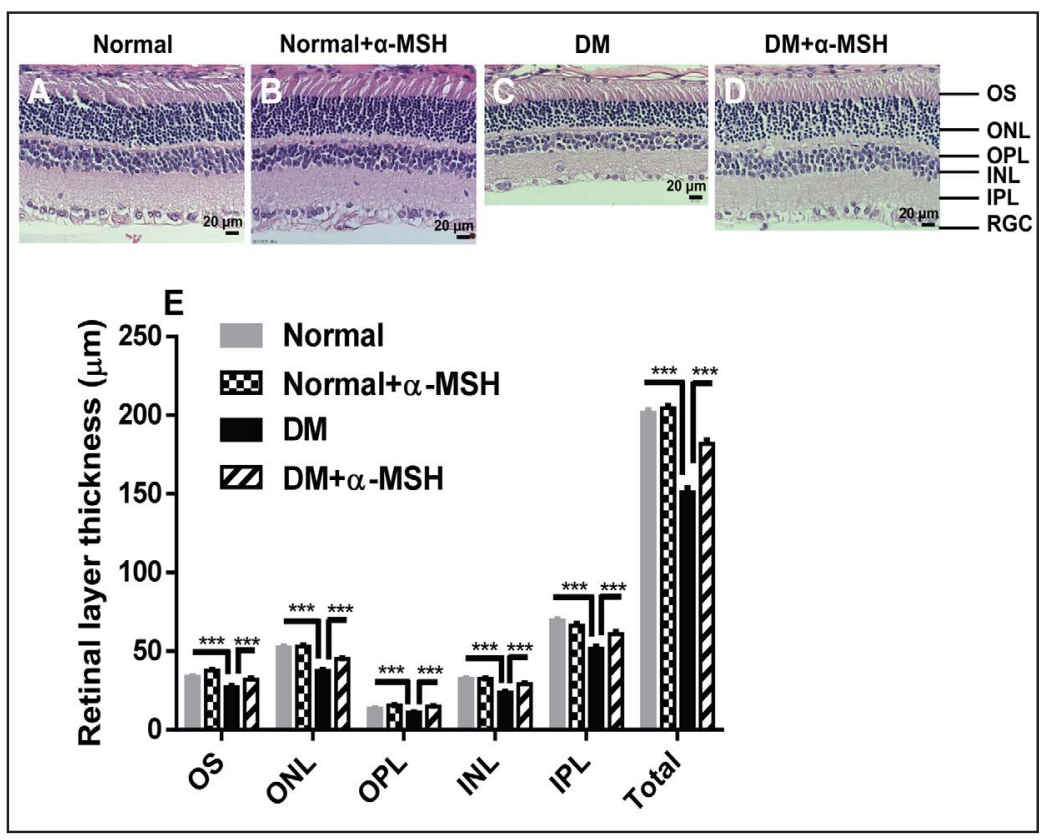
(gray) and normal $+\alpha$-MSH (checker) groups of rats. ${ }^{* * *} \mathrm{P}<0.001$. Scale bar $=20 \mu \mathrm{m}$.

and 8.77 fold, respectively, in diabetic retinas as compared to those in normal ones (Fig. 5A, C; $P<0.01$ for ICAM-1; $P<0.001$ for TNF- $\alpha$, normal vs DM), and these aberrant up-regulations were significantly subdued by $\alpha$-MSH (Fig. 5A, C; both $P<0.001$, DM vs $\alpha-\mathrm{MSH}+\mathrm{DM}$ ). These results confirmed our previous report [17]. Furthermore, the protein expression of ICAM-1 and TNF- $\alpha$, as examined by Western bots and ELISA, respectively, was also significantly upregulated in diabetic retinas (Fig. $5 \mathrm{~F}$ and $\mathrm{H}$, both $P<0.01$, Normal vs $\mathrm{DM}$ ), though to a less extent than the transcript expression (Fig. 5A, C, F, and H). Interestingly, the mRNA levels of occludin were significantly down-regulated in diabetic retinas, being only $45.61 \%$ of normal controls (Fig. 5B, $P<0.05$, normal vs DM). The reduced expression was normalized by intravitreal administration of $\alpha$-MSH (Fig. 5B, $P=0.803$, normal vs $\mathrm{DM}+\alpha-\mathrm{MSH}$ ). The protein expression of Occludin resembled the trend of its mRNA expression (Fig. 5B, E, G; $P<0.05$, normal vs DM; $P<0.05$, DM vs DM $+\alpha-\mathrm{MSH}$; $\mathrm{P}=0.715$, normal vs $\mathrm{DM}+\alpha$-MSH). These results indicate that $\alpha$-MSH may exert its protective effects on BRB in diabetic retinas through mitigating pro-inflammatory microenvironment and strengthening tight junctions at the molecular level.

On the other hand, the transcript levels of VEGF gene did not exhibit significant changes (Fig. 5D, $F=0.791, P=0.466$ ) among the experimental groups. However, the protein levels of VEGF, as determined by ELISA, were significantly elevated in the diabetic retinas as compared to the normal ones (Fig 5I, $P<0.01$, normal vs DM), and this elevation was reduced to the normal levels by $\alpha$-MSH treatment (Fig 5I, $P<0.05$, DM vs DM $+\alpha-\mathrm{MSH} ; P=0.788$, normal vs $\mathrm{DM}+\alpha-\mathrm{MSH})$. These results suggest that $\alpha$-MSH might also exert the anti-inflammation and anti-hyperpermeability effects in early diabetic retina via down-regulating VEGF expression at the protein level.

$\alpha$-MSH acts via MC4R to decrease permeability and increase TEER in HG-stimulated retinal microvessel endothelial cells

In the RF6A cells that had been stimulated with $27 \mathrm{mM} \mathrm{HG}$ for $8 \mathrm{~h}$, the expression of MC3R, MC4R, and MC5R, but not MC1R, was detected by regular PCR (Fig. 6A). The relative gene expression levels of MC3R, MC4R, and MC5R under normal and HG conditions were further analyzed by qPCR. The results showed that under normal condition, MC4R transcript 


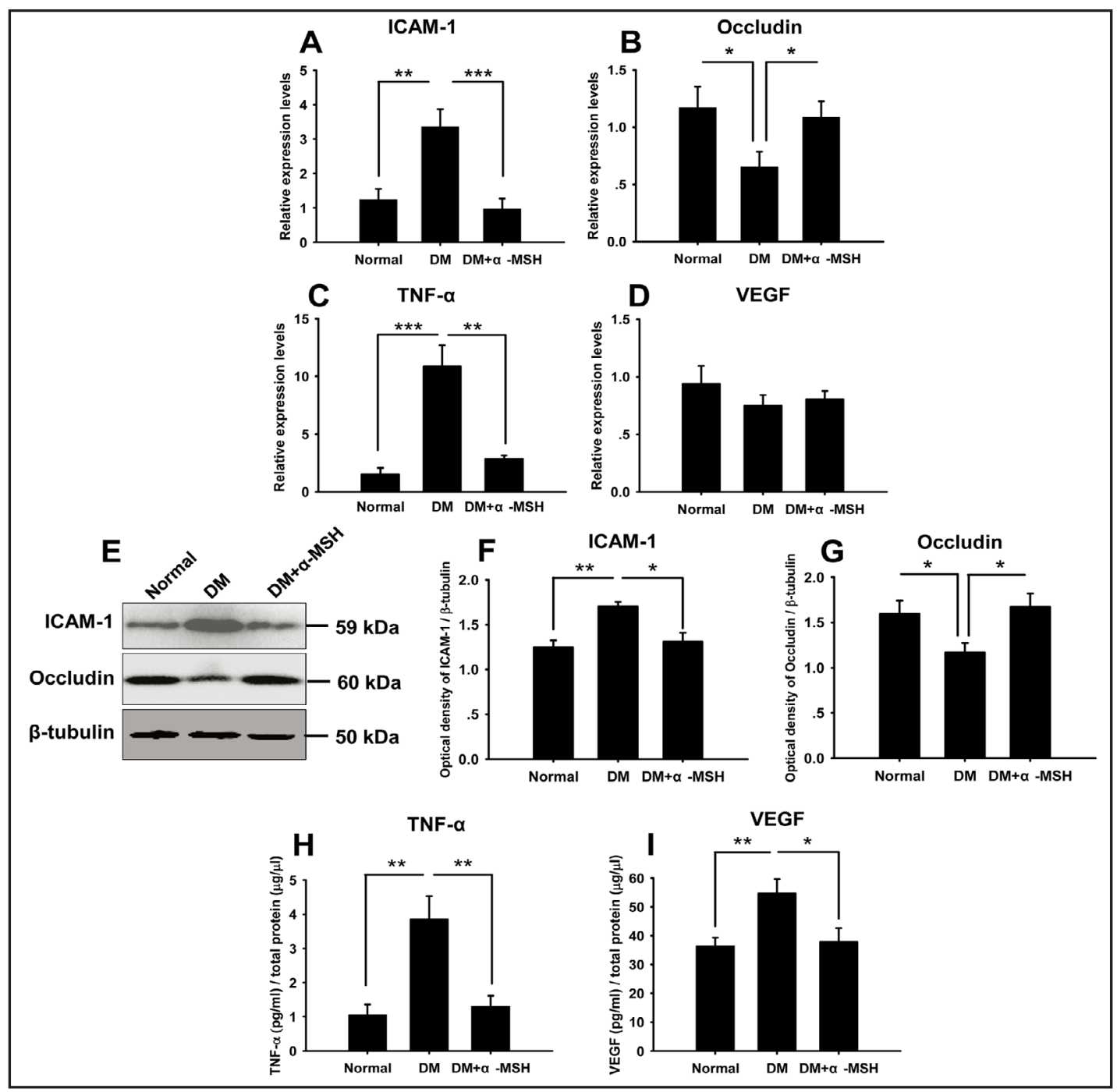

Fig. 5. $\alpha$-MSH corrected the aberrant gene expression at both mRNA and protein levels in diabetic retinas. The relative gene expression levels of ICAM-1 (A), occludin (B), TNF- $\alpha$ (C), and VEGF (D) were examined by qPCR. The protein expression of ICAM-1 and Occludin were detected by Western blots, the representatives of which were shown in (E). The protein levels of ICAM-1 (F) and Occludin (G) were normalized to that of internal standard $\beta$-tubulin. The protein concentrations of TNF- $\alpha(\mathrm{H})$ and VEGF $(\mathrm{I})$ were measured by ELISAs, and normalized to the total protein concentration. ${ }^{*} \mathrm{P}<0.05,{ }^{* *} \mathrm{P}<0.01$, *** $\mathrm{P}<0.001$.

levels were 38.87 and 4.15 fold higher than those of MC3R and MC5R, respectively (Fig. $6 \mathrm{~B}, P<0.001$, normal MC3R vs normal MC4R; $P<0.001$, normal MC4R vs normal MC5R). Following the $8 \mathrm{~h}-\mathrm{HG}$ treatment, MC3R and MC4R mRNA levels did not change (Fig. 6B, $P$ $=0.984$, normal MC3R vs HG MC3R; $P=0.713$, normal MC4R vs HG MC4R), whereas MC5R expression was significantly down-regulated as compared to the norm (Fig. 6B, $P<0.05$, normal MC5R vs HG MC5R). Therefore, MC4R is the predominant form of MCR either under the norm or HG stimulation in RF6A cells.

To test the anti-hyperpermeability effects of $\alpha$-MSH in the HG-stimulated retinal endothelial cells and to ascertain the receptor subtype mediating such effects, RF6A monolayer transwell culture was established, the TEER and permeability of the cells were determined at the presence of $\alpha-\mathrm{MSH}, \mathrm{MCR}$ blockers, and HG. The results showed that the TEER was significantly reduced following $8 \mathrm{~h}-\mathrm{HG}$ treatment, being only $57.27 \%$ of the normal control (Fig. 6C, $P<0.001$, HG vs normal). Correspondingly, the cell permeability, as reflected 
Fig. 6. $\alpha-\mathrm{MSH}$ prevented retinal microvessel endothelial cells from HG-induced hyperpermeability via MC4R. The expression of MCR subtypes in the monkey retinal microvessel endothelial (RF6A) cells was detected by regular PCR (A). The relative gene expression levels of MC3R, MC4R, and MC5R in RF6A cells under normal and HG conditions were analyzed by qPCR (B). The RF6A cells were

A
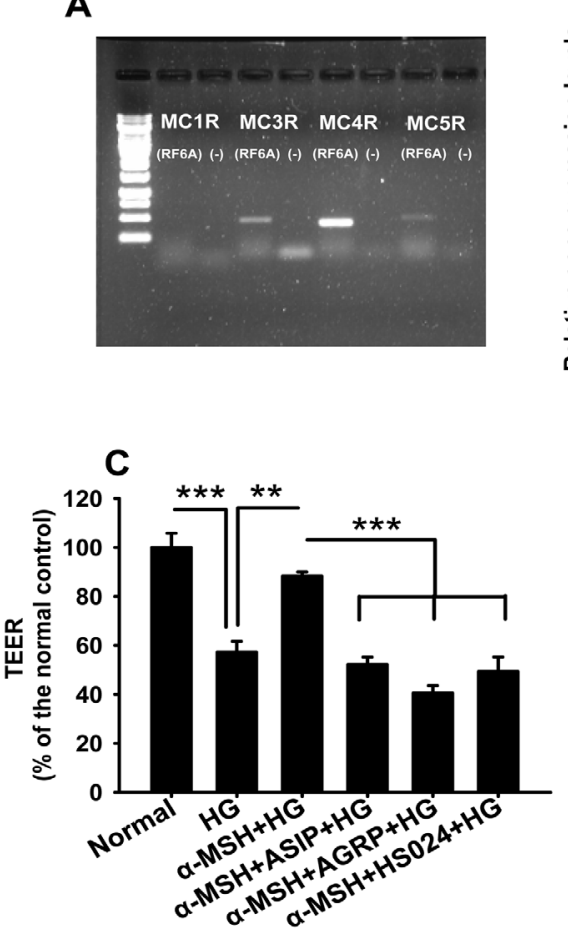
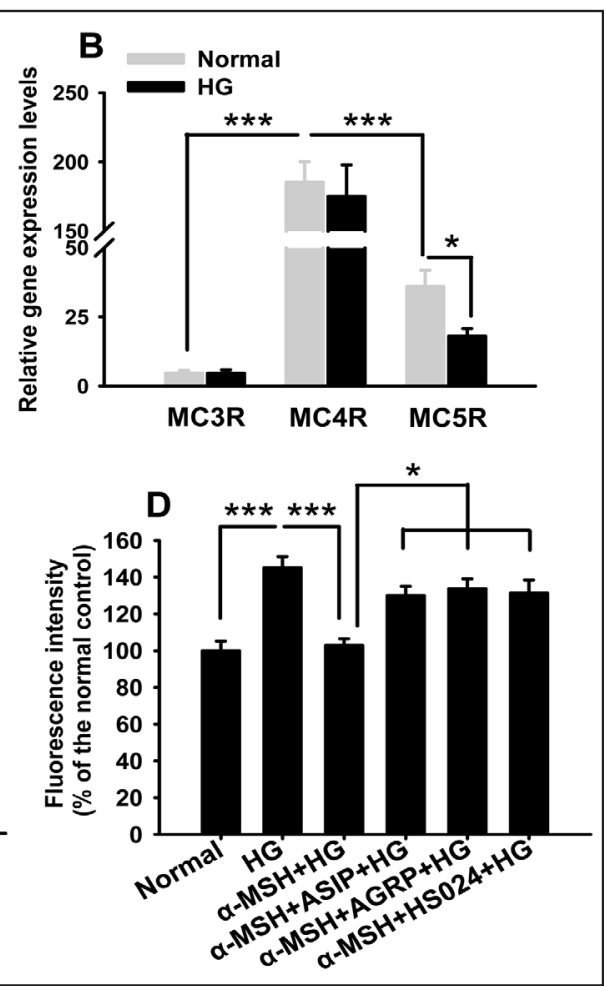
treated with normal or HG-containing media, $\alpha$-MSH, $\alpha$-MSH with a pan MCR blocker ASIP, $\alpha$-MSH with a MC3R and MC4R blocker AGRP, or $\alpha$-MSH with a specific MC4R blocker HS024 were added. The relative TEER (C) was measured. The relative permeability was determined by fluorescence intensity of FITC-Dextran transferred across RF6A cell monolayer (D). ${ }^{*} \mathrm{P}<0.05,{ }^{* *} \mathrm{P}<0.01$, *** $\mathrm{P}<0.001$.

by the fluorescence intensity of low molecular weight FITC-Dextran transferred through the cell monolayer, was boosted to $145.18 \%$ of the normal control (Fig. 6D, $P<0.001$, HG vs normal). The treatment of $\alpha$-MSH normalized the HG-induced aberrant alterations in TEER (Fig. 6C, $P<0.01$, HG vs $\alpha-\mathrm{MSH}+\mathrm{HG} ; P=0.150$, normal vs $\alpha-\mathrm{MSH}+\mathrm{HG}$ ) and permeability (Fig. $6 \mathrm{D}, P<0.001$, HG vs $\alpha$-MSH + HG; $P=0.1697$, normal vs $\alpha-\mathrm{MSH}+\mathrm{HG}$ ), suggesting $\alpha$-MSH's protection against hyperpermeability of retinal endothelial cells, a major cellular component of inner BRB. Furthermore, the universal MCR blocker ASIP, MC3R and MC4R blocker AGRP, and specific MC4R blocker HS024 exerted similar actions (Fig. 6C and D; ASIP + $\alpha-\mathrm{MSH}+\mathrm{HG}$ vs AGRP $+\alpha-\mathrm{MSH}+\mathrm{HG}, P=0.199$ for TEER, $P=0.626$ for permeability; ASIP $+\alpha-\mathrm{MSH}+\mathrm{HG}$ vs HS024 $+\alpha-\mathrm{MSH}+\mathrm{HG}, P=0.666$ for TEER, $P=0.887$ for permeability; AGRP $+\alpha-\mathrm{MSH}+\mathrm{HG}$ vs HS024 $+\alpha-\mathrm{MSH}+\mathrm{HG}, P=0.215$ for TEER, $P=0.793$ for permeability), and all abrogated $\alpha$-MSH's protective effects on TEER (Fig. $6 \mathrm{C}$, all $P<0.001, \alpha$-MSH + HG vs MCR blocker + $\alpha$-MSH + HG) and permeability (Fig. 6D, all $P<0.05, \alpha-\mathrm{MSH}+\mathrm{HG}$ vs MCR blocker $+\alpha-\mathrm{MSH}$ $+\mathrm{HG}$ ). These results, in view of the MCR gene expression profiling (Fig. 6A, B), indicate that MC4R is the receptor subtype that predominantly mediates $\alpha$-MSH's anti-hyperpermeability in retinal microvessel endothelial cells stimulated with HG.

\section{Discussion}

The current study demonstrated the previously undescribed effects of $\alpha$-MSH on protecting early diabetic retinas from BRB breakdown and vascular leakage both qualitatively and quantitatively (Fig. 1), improving ultrastructures of choroidal and retinal microvessels (Fig. 2), restoring electrophysiological functions (Fig. 3), and maintaining retinal morphology 


\section{Cellular Physiology Cell Physiol Biochem 2018;45:505-522 \\ \begin{tabular}{ll|l} 
DOI: 10.1159/000487029 & O 2018 The Author(s). Published by S. Karger AG, Basel \\
and Biochemistry & Published onnine: January 31, 2018 .
\end{tabular}}

Cai et al.: A-MSH Protects Early Diabetic Retina from Vascular Leakage

(Fig. 4) in the STZ-induced rat model of diabetes. Mechanistically, the protective effects could be ascribed to $\alpha$-MSH's subduing the upregulation of pro-inflammatory and propermeability factors and boosting tight junction protein in diabetic retinas (Fig. 5). Further, the in vitro studies suggest that $\alpha$-MSH acts predominantly via MC4R to inhibit the HGinduced hyperpermeability in a retinal microvessel endothelial cell transwell culture (Fig. 6), thereby revealing a novel protective role of MC4R at the interface of BRB.

The traditional and effective Evans blue assay was used to detect and quantify the BRB breakdown and retinal vascular leakage at W 5 following diabetic onset. The results are consistent with numerous reports that BRB breakdown and vascular leakage can be detected in the STZ-induced diabetic rat model at W $1 \sim 5$ after induction using either Evans blue assay $[19,20,31,32]$ or other methods [33, 34]. Therefore, the BRB breakdown and vessel leakage is one of the early signs of retinal damage in diabetic rats, the pathology of which is similar to early stage of human DR [3]. Moreover, the modifications to Evans blue assay proposed by $\mathrm{Xu}$ et al. [19], including increasing dye dosage, prolonging circulation time, normalizing to retina dry weight, reducing volume of organic extractant, and multiple readings of absorbance with correction, were strictly followed to increase the sensitivity and reproducibility of the assay in diabetic retinas. Yet, it has been reported that pneumothorax, acidic perfusion solution, and the pressure used for intraventricular perfusion could cause disruptions in the BRB, thereby generating the artifacts of vascular leakage during Evans blue assay [35]. However, it bears noting that these procedures in Evans blue assay are equally applied to all experimental animals, and there is no evidence that the procedures would be more deleterious to the BRB functions in diabetic rats than in normal counterparts [35]. Therefore, the influence of these procedures could be offset during the statistical comparisons between the experimental groups. On the other hand, an intravenous injection of a biotinylated bovine serum albumin (bBSA) has been used as an alternative to Evans blue assay [36]. Following blood circulation and thorough perfusion, the extravasated bBSA was measured by either immunoprecipitation and Western blot or ELISA [36]. Although the alternative bBSA approach is streamlined and adapted to mouse retina, this approach detects the biological behavior of an exogenous protein across the BRB under either normal or pathological conditions. It remains unknown whether this approach can accurately reflect the behavior of endogenous macromolecules across the BRB. Whereas the Evans blue assay detects the blue dye that binds to endogenous macromolecules and leaks through the damaged BRB into retina parenchyma, thereby reflecting permeability of endogenous proteins $[18,19]$. In our opinion, despite the potential confounding factors, the Evans blue assay could reflect the permeability trend of endogenous macro-proteins and may be used to quantify the BRB breakdown and vascular leakage in diabetic retinas, particularly in rats.

The attenuation of retinal layers in diabetic retinas at W 5 after hyperglycemia (Fig. 4C, E) is consistent with the literature report [20]. The preservation of retinal layer thickness and structural organization in the $\alpha$-MSH-treated diabetic retinas (Fig. 4D, E) suggests that this peptide counteracts retinal degeneration occurred during early diabetes, and this result is fundamentally in agreement with $\alpha$-MSH's anti-apoptotic effects in diabetic retinas described in our previous study [17]. Moreover, the morphology maintenance may account, at least in part, for the recovery of retinal electrophysiological functions, including a wave implicit time, a wave and b wave amplitudes, in diabetic retinas intravitreally administered with $\alpha$-MSH (Fig. 3).

The molecular mechanisms underlying $\alpha$-MSH's protection on BRB in diabetic retinas were investigated. First, $\alpha$-MSH significantly reduced the overexpression of pro-inflammatory factors ICAM-1 and TNF- $\alpha$ at both mRNA and protein levels in diabetic retinas (Fig. 5A, C, F, H). These data confirmed our previous gene expression analyses [17], implicating that $\alpha$-MSH can alleviate the pro-inflammatory microenvironment caused by hyperglycemia and oxidative stress in diabetic retina. Second, $\alpha$-MSH augmented the expression of occludin at both transcript and protein levels in diabetic retinas (Fig. 5B, G). Occludin is a key protein component of BRB [24]. This result suggests that this peptide may enhance BRB functions via fortifying tight junctions. Last, no significant difference was found in VEGF mRNA levels 
among experimental groups (Fig. 5D). There are discrepancies in the literature concerning VEGF transcript levels in early diabetic rat retinas [21, 37-40]. The discrepancies may, in part, result from the complexity of VEGF family, which comprises VEGF-A, placenta growth factor, VEGF-B, VEGF-C, and VEGF-D [41]. Among these family members, VEGF-A is most closely related to vessel hyperpermeability and neovascularization [42]. Furthermore, 9 splicing variants of VEGF-A transcript have been identified in rat, 6 of them (NM_031836.3, NM_001110333.2, NM_001110334.2, NM_001287111.1, NM_001287113.1, and NM_001287114.1) have been confirmed to encode protein isoforms in reality. Therefore, the qPCR primers for VEGF were designed according to the common sequence of these 6 splicing variants (Table 1), and the qPCR results represent the total mRNA levels of the 6 variants. The differential expression in any of the variant under diabetic condition could be "diluted" when ensemble transcript levels are determined, thereby leading to insignificant mRNA levels among experimental groups (Fig. 5D). Nevertheless, the protein levels of VEGF, detected by a commercially available ELISA kit, were significantly elevated in the diabetic retinas, which were reduced to the normal levels by $\alpha$-MSH's treatment (Fig. 5I), suggesting $\alpha$-MSH's inhibition on the protein expression of this pro-inflammatory and pro-permeability factor in early diabetic retinas.

The $\alpha$-MSH / MC4R-mediated neuroprotective effects have been reported in the literature. For example, $\alpha-\mathrm{MSH}$, through activation of MC4R, ameliorates brain damage and cognition decline in mammalian models of cerebral ischemia [43] and Alzheimer's disease [44], respectively. We have also shown that $\alpha$-MSH acts via MC4R to antagonize glutamateinduced excitotoxicity in developing chicken retinas [23]. In the current study, we first detected the predominant expression of MC4R in simian retinal microvessel endothelial cells under both norm and HG stimulation (Fig. 6A, B), indicating an important role of this subtype of MCR in the endothelial cells. Further, in an in vitro model of inner BRB, universal and specific MCR blockers were used to systematically prove and confirm the predominant role of MC4R in mediating $\alpha$-MSH's anti-hyperpermeability in the endothelial cells (Fig. 6C, D). These results reveal a novel role of MC4R at the BRB, sharing of the protective MCR subtype between BRB and neuroretina may facilitate efficient regulation by hormones and modulators and integration into a functional neurovascular unit [45].

\section{Conclusion}

In summary, intravitreal injections of $\alpha$-MSH protect against BRB breakdown, reduce vascular leakage, improve ultrastructures of choroidal and retinal microvessels, rescue electrophysiological functions, and maintain general morphology in rat retinas of early diabetes. These protective effects may be ascribed to mitigating pro-inflammatory microenvironment and strengthening tight junctions in diabetic retinas. The protective effects of $\alpha$-MSH / MC4R system extend to the BRB.

\section{Acknowledgements}

This research work was supported by the grants from the key projects of Tianjin Municipal Science and Technology Commission (17JCZDJC35600 to Y.Z., 14JCZDJC36200 to C.Q.); Ph.D. Programs Foundation of Ministry of Education of China (\# 20121202120005 to Y.Z.); the $45^{\text {th }}$ Scientific Research Foundation for the Returned Overseas Chinese Scholars, State Education Ministry to Y.Z; the start-up fund for introduction of talents to Tianjin Medical University Eye Hospital (\# TJEC20101110 to Y.Z.); Ph.D. Programs Foundation of Ministry of Education of China (\# 20111202110008 to X.L.).

\section{Disclosure Statement}

The authors declare no conflicts of interest in this work. 


\section{Cellular Physiology Cell Physiol Biochem 2018;45:505-522

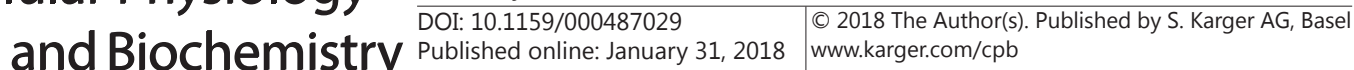

\section{References}

1 Tan GS, Cheung N, Simo R, Cheung GC, Wong TY: Diabetic macular oedema. Lancet Diabetes Endocrinol 2017;5:143-155.

-2 Das A, McGuire PG, Rangasamy S: Diabetic macular edema: Pathophysiology and novel therapeutic targets. Ophthalmology 2015;122:1375-1394.

-3 Klaassen I, Van Noorden CJ, Schlingemann RO: Molecular basis of the inner blood-retinal barrier and its breakdown in diabetic macular edema and other pathological conditions. Prog Retin Eye Res 2013;34:19-48.

-4 Fogli S, Mogavero S, Egan CG, Del RM, Danesi R: Pathophysiology and pharmacological targets of VEGF in diabetic macular edema. Pharmacol Res 2016;103:149-157.

-5 Wong TY, Cheung CM, Larsen M, Sharma S, Simo R: Diabetic retinopathy. Nat Rev Dis Primers 2016;2:16012.

6 Ehrlich R, Harris A, Ciulla TA, Kheradiya N, Winston DM, Wirostko B: Diabetic macular oedema: Physical, physiological and molecular factors contribute to this pathological process. Acta Ophthalmol 2010;88:279291.

7 Mathew C, Yunirakasiwi A, Sanjay S: Updates in the management of diabetic macular edema. J Diabetes Res 2015;2015:794036.

8 Zhang L, Wang W, Gao Y, Lan J, Xie L: The efficacy and safety of current treatments in diabetic macular edema: A systematic review and network Meta-Analysis. PLoS One 2016;11:e159553.

9 Wardlaw SL: Hypothalamic proopiomelanocortin processing and the regulation of energy balance. Eur J Pharmacol 2011;660:213-219.

10 Yang Y: Structure, function and regulation of the melanocortin receptors. Eur J Pharmacol 2011;660:125-130.

11 Zhang Y, Wu X, He Y, Kastin AJ, Hsuchou H, Rosenblum CI, Pan W: Melanocortin potentiates leptin-induced STAT3 signaling via MAPK pathway. J Neurochem 2009;110:390-399.

12 Zhang Y, Kerman IA, Laque A, Nguyen P, Faouzi M, Louis GW, Jones JC, Rhodes C, Munzberg H: Leptinreceptor-expressing neurons in the dorsomedial hypothalamus and median preoptic area regulate sympathetic brown adipose tissue circuits. J Neurosci 2011;31:1873-1884.

13 Nohara K, Zhang Y, Waraich RS, Laque A, Tiano JP, Tong J, Munzberg H, Mauvais-Jarvis F: Early-life exposure to testosterone programs the hypothalamic melanocortin system. Endocrinology 2011;152:1661-1669.

14 Clemson CM, Yost J, Taylor AW: The role of Alpha-MSH as a modulator of ocular immunobiology exemplifies mechanistic differences between melanocortins and steroids. Ocul Immunol Inflamm 2017;25:179-189.

15 Taylor AW, Lee D: Applications of the role of alpha-MSH in ocular immune privilege. Adv Exp Med Biol 2010;681:143-149.

16 Lee DJ, Biros DJ, Taylor AW: Injection of an alpha-melanocyte stimulating hormone expression plasmid is effective in suppressing experimental autoimmune uveitis. Int Immunopharmacol 2009;9:1079-1086.

17 Zhang L, Dong L, Liu X, Jiang Y, Zhang L, Zhang X, Li X, Zhang Y: Alpha-Melanocyte-stimulating hormone protects retinal vascular endothelial cells from oxidative stress and apoptosis in a rat model of diabetes. PLoS One 2014;9:e93433.

18 Qaum T, Xu Q, Joussen AM, Clemens MW, Qin W, Miyamoto K, Hassessian H, Wiegand SJ, Rudge J, Yancopoulos GD, Adamis AP: VEGF-initiated blood-retinal barrier breakdown in early diabetes. Invest Ophthalmol Vis Sci 2001;42:2408-2413.

-19 Xu Q, Qaum T, Adamis AP: Sensitive blood-retinal barrier breakdown quantitation using Evans blue. Invest Ophthalmol Vis Sci 2001;42:789-794.

-20 Zhang J, Wu Y, Jin Y, Ji F, Sinclair SH, Luo Y, Xu G, Lu L, Dai W, Yanoff M, Li W, Xu GT: Intravitreal injection of erythropoietin protects both retinal vascular and neuronal cells in early diabetes. Invest Ophthalmol Vis Sci 2008;49:732-742.

21 Hu B, Zhang Y, Zeng Q, Han Q, Zhang L, Liu M, Li X: Intravitreal injection of ranibizumab and CTGF shRNA improves retinal gene expression and microvessel ultrastructure in a rodent model of diabetes. Int J Mol Sci 2014;15:1606-1624.

22 Ru Y, Huang Y, Liu H, Du J, Meng Z, Dou Z, Liu X, Wei RH, Zhang Y, Zhao S: Alpha-Melanocyte-stimulating hormone ameliorates ocular surface dysfunctions and lesions in a scopolamine-induced dry eye model via PKA-CREB and MEK-Erk pathways. Sci Rep 2015;5:18619.

23 Zhang Y, Bo Q, Wu W, Xu C, Yu G, Ma S, Yang Q, Cao Y, Han Q Ru Y, Liu X, Hua WR, Wang FE, Zhang X, Li X: Alpha-Melanocyte-stimulating hormone prevents glutamate excitotoxicity in developing chicken retina via MC4R-mediated down-regulation of microRNA-194. Sci Rep 2015;5:15812. 


\section{Cellular Physiology Cell Physiol Biochem 2018;45:505-522 \begin{tabular}{c|c|c|c|} 
DOI: 10.1159/000487029 & C 2018 The Author(s). Published by S. Karger AG, Basel \\
www.karger.com/cpb
\end{tabular}

-24 Kask A, Mutulis F, Muceniece R, Pahkla R, Mutule I, Wikberg JE, Rago L, Schioth HB: Discovery of a novel superpotent and selective melanocortin-4 receptor antagonist (HS024): Evaluation in vitro and in vivo. Endocrinology 1998;139:5006-5014.

25 Ni Y, Teng T, Li R, Simonyi A, Sun GY, Lee JC: TNFalpha alters occludin and cerebral endothelial permeability: Role of p38MAPK. PLoS One 2017;12:e170346.

-26 Kaneko Y, Ohta M, Inoue T, Mizuno K, Isobe T, Tanabe S, Tanihara H: Effects of K-115 (Ripasudil), a novel ROCK inhibitor, on trabecular meshwork and Schlemm's canal endothelial cells. Sci Rep 2016;6:19640.

27 Cunha-Vaz J, Bernardes R, Lobo C: Blood-retinal barrier. Eur J Ophthalmol 2011;21:S3-S9.

-28 Kaur C, Foulds WS, Ling EA: Blood-retinal barrier in hypoxic ischaemic conditions: Basic concepts, clinical features and management. Prog Retin Eye Res 2008;27:622-647.

29 Kumar B, Gupta SK, Srinivasan BP, Nag TC, Srivastava S, Saxena R, Jha KA: Hesperetin rescues retinal oxidative stress, neuroinflammation and apoptosis in diabetic rats. Microvasc Res 2013;87:65-74.

-30 Chen W, Yao X, Zhou C, Zhang Z, Gui G, Lin B: Danhong huayu koufuye prevents diabetic retinopathy in Streptozotocin-Induced diabetic rats via antioxidation and Anti-Inflammation. Mediators Inflamm 2017;2017:3059763.

-31 Paterniti I, Di Paola R, Campolo M, Siracusa R, Cordaro M, Bruschetta G, Tremolada G, Maestroni A, Bandello F, Esposito E, Zerbini G, Cuzzocrea S: Palmitoylethanolamide treatment reduces retinal inflammation in streptozotocin-induced diabetic rats. Eur J Pharmacol 2015;769:313-323.

-32 Kusari J, Zhou S, Padillo E, Clarke KG, Gil DW: Effect of memantine on neuroretinal function and retinal vascular changes of streptozotocin-induced diabetic rats. Invest Ophthalmol Vis Sci 2007;48:5152-5159.

33 Kim SR, Im JE, Jeong JH, Kim JY, Kim JT, Woo SJ, Sung JH, Park SG, Suh W: The cKit inhibitor, masitinib, prevents Diabetes-Induced retinal vascular leakage. Invest Ophthalmol Vis Sci 2016;57:1201-1206.

-34 Feng Y, Wang R, Xu J, Sun J, Xu T, Gu Q Wu X: Hydrogen-rich saline prevents early neurovascular dysfunction resulting from inhibition of oxidative stress in STZ-diabetic rats. Curr Eye Res 2013;38:396-404.

-35 Berkowitz BA, Roberts R, Luan H, Peysakhov J, Mao X, Thomas KA: Dynamic contrast-enhanced MRI measurements of passive permeability through blood retinal barrier in diabetic rats. Invest Ophthalmol Vis Sci 2004;45:2391-2398.

-36 Trichonas G, Manola A, Morizane Y, Thanos A, Koufomichali X, Papakostas TD, Montezuma S, Young L, Miller JW, Gragoudas E, Vavvas D: A novel nonradioactive method to evaluate vascular barrier breakdown and leakage. Invest Ophthalmol Vis Sci 2010;51:1677-1682.

37 Gong CY, Lu B, Hu QW, Ji LL: Streptozotocin induced diabetic retinopathy in rat and the expression of vascular endothelial growth factor and its receptor. Int J Ophthalmol 2013;6:573-577.

38 Yang H, Huang Y, Chen X, Liu J, Lu Y, Bu L, Xia L, Xiao W, Chen M, Nie Q Liu Z: The role of CTGF in the diabetic rat retina and its relationship with VEGF and TGF-beta(2) , elucidated by treatment with CTGFsiRNA. Acta Ophthalmol 2010;88:652-659.

39 Masuzawa K, Goto K, Jesmin S, Maeda S, Miyauchi T, Kaji Y, Oshika T, Hori S: An endothelin type A receptor antagonist reverses upregulated VEGF and ICAM-1 levels in streptozotocin-induced diabetic rat retina. Curr Eye Res 2006;31:79-89.

40 Xu X, Zhu Q Xia X, Zhang S, Gu Q, Luo D: Blood-retinal barrier breakdown induced by activation of protein kinase $\mathrm{C}$ via vascular endothelial growth factor in streptozotocin-induced diabetic rats. Curr Eye Res 2004;28:251-256.

41 Shinkaruk S, Bayle M, Lain G, Deleris G: Vascular endothelial cell growth factor (VEGF), an emerging target for cancer chemotherapy. Curr Med Chem Anticancer Agents 2003;3:95-117.

42 Zhang Y, Cai S, Jia Y, Qi C, Sun J, Zhang H, Wang F, Cao Y, Li X: Decoding noncoding RNAs: Role of MicroRNAs and long noncoding RNAs in ocular neovascularization. Theranostics 2017;7:3155-3167.

43 Giuliani D, Mioni C, Altavilla D, Leone S, Bazzani C, Minutoli L, Bitto A, Cainazzo MM, Marini H, Zaffe D, Botticelli AR, Pizzala R, Savio M, Necchi D, Schioth HB, Bertolini A, Squadrito F, Guarini S: Both early and delayed treatment with melanocortin 4 receptor-stimulating melanocortins produces neuroprotection in cerebral ischemia. Endocrinology 2006;147:1126-1135.

44 Giuliani D, Galantucci M, Neri L, Canalini F, Calevro A, Bitto A, Ottani A, Vandini E, Sena P, Sandrini M, Squadrito F, Zaffe D, Guarini S: Melanocortins protect against brain damage and counteract cognitive decline in a transgenic mouse model of moderate Alzheimer's disease. Eur J Pharmacol 2014;740:144-150.

-45 Antonetti DA, Klein R, Gardner TW: Diabetic retinopathy. N Engl J Med 2012;366:1227-1239. 